\title{
Evaluation of Co-Ni/SiC Nanocomposite Coating Obtained by Electrodeposition on the Corrosion Resistance of API $5 \mathrm{~L}$ X80 Steel
}

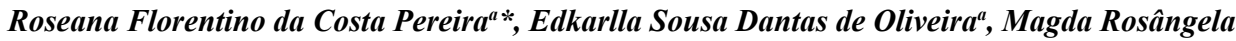 \\ Santos Vieira ${ }^{a}$, Maria Alice Gomes de Andrade Lima ${ }^{b}$, Severino Leopoldino Urtiga Filho ${ }^{a}$ \\ ${ }^{a}$ Department of Mechanical Engineering, Universidade Federal de Pernambuco - \\ UFPE, CEP 50730-530, Recife, PE, Brazil \\ ${ }^{b}$ Department of Chemical Engineering, Universidade Federal de Pernambuco - UFPE, \\ CEP 50740-521, Recife, PE, Brazil
}

Received: January 11, 2017; Revised: April 26, 2017; Accepted: June 03, 2017

\begin{abstract}
$\mathrm{Co}-\mathrm{Ni} / \mathrm{SiC}$ nanocomposite coatings were obtained by codeposition of $\mathrm{SiC}$ nanoparticles in a bath with nickel and cobalt, using API 5L X80 as the substrate. The influence of cathodic current density on deposit properties was investigated. Measurements of electrochemical impedance spectroscopy (EIS) and potentiodynamic polarization (PP) were performed in $3.5 \mathrm{wt} \% \mathrm{NaCl}$ solution to investigate a corrosion performance. The morphology and chemical analysis of the surfaces were analyzed by scanning electron microscopy (SEM) coupled with energy dispersive spectroscopy (EDS) and related with micro-hardness and X-ray diffraction (XRD). The results indicate which composite coatings have acicular morphology, with higher micro-hardness values than those found for the carbon steel substrate. The $\mathrm{Co}-\mathrm{Ni} / \mathrm{SiC}$ coating increased the corrosion potential and the resistance to polarization, which resulted in lower corrosion rates than those obtained without uncoated steel.
\end{abstract}

Keywords: $\mathrm{Ni}$-Co/Si nanocomposite, electrodeposition, corrosion resistance, carbon steel

\section{Introduction}

There has been a considerable increase in the interest in investigating composite coatings due to their unique mechanical properties, self-lubricity, thermal stability, oxidation, corrosion and wear resistance ${ }^{1,2}$. Composite electrodeposition refers to a process in wich particles are suspended in the electrolyte and subsequentely embedded into an electro-formed solid phase $\mathrm{e}^{3}$. Over the past decades, successful co-deposition of different types of particles such as oxide $^{2}$, carbide $^{3}$, polymer $^{4}$, nitride 5 , diamond ${ }^{6}$, graphite $^{7}$ and metallic ${ }^{3,5,7}$ particles has been reported. Among the various composite coating systems produced by the combination of different matrix and reinforcement materials, $\mathrm{Ni} / \mathrm{SiC}$ composite coatings have been widely studied in order to explore the impact of the co-deposition conditions and the properties of the deposited coatings. Recently, more attention has been paid to the synthesis of composite coatings by codeposition of reinforcing particles in the alloy matriced like $\mathrm{Ni}-\mathrm{W}^{5,7}, \mathrm{Zn}-\mathrm{Ni}^{7,8}, \mathrm{Ni}-\mathrm{Fe}^{9}$ and particularly $\mathrm{Co}-\mathrm{Ni}$ alloys ${ }^{5-7}$. However, only few investigations have been made regarding the electrodeposition of $\mathrm{Co}-\mathrm{Ni} / \mathrm{SiC}$ nanocomposite coatings, which may feature favorable mechanical, corrosion and tribological properties ${ }^{10}$.

Besides that, Ni-Co metal matrix composite coatings have widely attracted attention due to its hardness and corrosion resistance as a replacement for hard chromium coating ${ }^{2,8}$. Ni-Co based composite coatings are expected to be applied in automobile, aerospace and other industrial fields owing to their good adhesion to the substrate's low residual stress, high hardness, anti-wear and anti-corrosion properties ${ }^{6,7,11}$.

Yang \& $\mathrm{Cheng}^{3}$ prepared $\mathrm{Ni}-\mathrm{Co} / \mathrm{SiC}$ composite coatings by pulse current (PC) electrodeposition on X65 carbon steel and found that the coating morphology changes from a nodular to an acicular structure with finer grains besides the micro-hardness and corrosion resistance that was enhanced with the amount of SiC nanoparticles deposited. Bakhit et al. ${ }^{8}$ found that the highest percentage of $\mathrm{SiC}$ nanoparticles (8.1 vol.\%) in the $\mathrm{Ni}-\mathrm{Co} / \mathrm{SiC}$ nanocomposite coatings was achieved at $2 \mathrm{~A} \mathrm{dm}^{-2}$ deposition current density and $5 \mathrm{~g} \mathrm{~L}^{-1}$ particle concentration, in plates of brass as substrate. The author indicated that the corrosion resistance of the $\mathrm{Ni}-\mathrm{Co} /$ $\mathrm{SiC}$ nanocomposite coatings was markedly higher than the corrosion resistance of the Ni-Co alloy coatings.

It is important that the electrodeposition is studied on various substrates beacuse of the influence of hydrogen evolution on the formation of the deposit ${ }^{9,10}$. Despite many previous works in this area, few studies have focused on $\mathrm{Co}-\mathrm{Ni} / \mathrm{SiC}$ nanocomposite coating prepared on carbon steel surface $^{3,5,11}$ - very important material in the industry and that requires protection forms. The production of the $\mathrm{Ni}-\mathrm{Co} / \mathrm{SiC}$ nanocomposite coatings in carbon steel implies adequating existing methodologies that have been developed for less 
complex substrates (i.e. copper, nickel, glassy carbon) in order to obtain the optimization of deposit properties ${ }^{12}$.

This paper aims to investigate the electrodeposition and characteristics of $\mathrm{Co}-\mathrm{Ni} / \mathrm{SiC}$ composite coating in carbon steel using the galvanostatic technique. The influence of the cathodic current density on microstructure and corrosion properties of the $\mathrm{Co}-\mathrm{Ni} / \mathrm{SiC}$ nanocomposite was analysed and related with the substrate. The morphology surface, the chemical composition and the crystalline structure of the nanocomposite were characterized by scanning electron microscopy (SEM) coupled with energy-dispersive X-ray spectrum (EDXS) and X-ray diffraction (XRD). The microhardness and corrosion resistance of the coating were measured and related with the $\mathrm{SiC}$ content. Eventually, the corrosion resistance of the coatings and the substrate in a 3.5 wt. $\% \mathrm{NaCl}$ solution was investigated.

\section{Methodology}

\subsection{Specimens' preparation}

Specimens with approximate dimensions of $15 \mathrm{~mm} \times 10$ $\mathrm{mm} \times 6 \mathrm{~mm}$ were cut from an API 5L X80 steel tube, with a chemical composition (wt.\%): C 0.030, S 0.004, Cr 0.159, Mn 1.72, Si 0.170, Al 0.028 and residual Fe. All sides of the specimen were sealed with epoxy leaving a rectangular working area of $1.5 \mathrm{~cm}^{2}$, which was used to obtain the coatings and for all characterization analyzes. Prior to the electrodeposition, the working face was ground sequentially with 220,320, 400 and 600 grit emery papers and polished with a $1 \mu \mathrm{m} \mathrm{Al}_{2} \mathrm{O}_{3}$ powder suspension ${ }^{3}$. The specimens were then washed in an electrolyte containing $30 \mathrm{~g} / \mathrm{L} \mathrm{Na}_{2} \mathrm{CO}_{3}$ and $10 \mathrm{~g} / \mathrm{L} \mathrm{NaOH}$ at room temperature $\left(\sim 25^{\circ} \mathrm{C}\right)$, and activated in $1: 1(\mathrm{v} / \mathrm{v}) \mathrm{HCl}$ solution for $20 \mathrm{~s}^{12}$.

\subsection{Electrolyte and electrodepositing parameters}

The electrolyte bath for electrodeposition was prepared according to the composition ${ }^{3}$ of Table 1 . SiC nano-powder with an average grain diameter of 50-60 nm was used. All chemicals were analytic grade reagents. The particle agglomeration was prevented by suspending the $\mathrm{SiC}$ nanoparticles in the electrolyte bath under a magnetic stirring at $600 \mathrm{rpm}$ for 24 hours before and was done during the plating ${ }^{8}$.

The electrodepositing condition included a direct cathodic current density ranging $20-50 \mathrm{~mA} / \mathrm{cm}^{2}$, a depositing time of $60 \mathrm{~min}$, an electrolyte speed of $600 \mathrm{rpm}$ and temperature of $55^{\circ} \mathrm{C}$. The electrodeposition was carried out using AUTOLAB Galvanostat/Potentiostat, controlled by NOVA 1.11 program, where the steel specimens were used as cathode and a platine helical as anode. During the electrodeposition, the chronopotentiometric monitoring was performed.
Table 1. Electrodeposition parameters for the preparation of $\mathrm{Co}-\mathrm{Ni} / \mathrm{SiC}$ coatings.

\begin{tabular}{lc}
\hline Bath composition & \\
\hline Electrolyte & Concentration $\left(\mathrm{g} \mathrm{L}^{-1}\right)$ \\
\hline $\mathrm{NiSO}_{4} \cdot 7 \mathrm{H}_{2} \mathrm{O}$ & 200 \\
$\mathrm{NiCl}_{2} \cdot 6 \mathrm{H}_{2} \mathrm{O}$ & 70 \\
$\mathrm{CoSO}_{4} \cdot 7 \mathrm{H}_{2} \mathrm{O}$ & 60 \\
Sodium citrate & 30 \\
Boric acid & 30 \\
SiC nanoparticles 50-60 nm & 30 \\
\hline Electrodeposition conditions & \\
\hline pH & $4.5 \pm 0,1$ \\
Temperature $\left({ }^{\circ} \mathrm{C}\right)$ & $55 \pm 1$ \\
Cathodic current density $(\mathrm{A} \mathrm{dm}$ & -2 \\
Stirring speed (rpm) & $2,3,4,5,6$ \\
Electrodeposition time (min) & 600
\end{tabular}

\subsection{SEM and EDXS characterization}

The morphology of the nanocomposites was observed by using a model Tecsan Mira 3 scanning electron microscope, and the composition of the deposit was determined by EDXS combined with SEM. The cross-section of the coating was observed and the thickness measured ${ }^{13}$.

\subsection{XRD characterization}

To determine the crystalline orientation and the grain size, XRD measurements were carried out by using a Shimadzu XRD-7000 diffractometer employing $\mathrm{Cu} \mathrm{K} \alpha$ radiation of wavelength $0.154 \mathrm{~nm}$. The scan rate was $0.05^{\circ}$ per second over a $2 \theta$ ranging from $20^{\circ}$ to $100^{\circ}$.

\subsection{Micro-hardness measurement}

The micro-hardness of the nanocomposites was measured using a Vickers diamond indenter at an applied load of $200 \mathrm{~g}$ for $15 \mathrm{~s}$. Ten measurements were conducted on each sample to obtain the average value ${ }^{14}$. For comparison purposes, these measurements were performed in steel and nanocomposites.

\subsection{Corrosion resistance}

Corrosion tests ${ }^{15}$ were performed on the electrolyte/ coating and electrolyte/base metal systems, using a typical three-electrode cell containing $100 \mathrm{~mL}$ : where the steel or nanocomposites were used as working electrode (WE), a platinum electrode as counter electrode (CE), and an $\mathrm{Ag} / \mathrm{AgCl}$ electrode as reference electrode (RE), using the potentiostat AUTOLAB GALVANOSTAT. All corrosion tests were conduced in $3.5 \mathrm{wt} \% \mathrm{NaCl}$ solution at room temperature, after 24 hours of immersion to stabilize the corrosion potential. 
Potentiodynamic polarization curves (PP) were obtained at $0.1 \mathrm{mV} / \mathrm{min}$ scanning rate and the scanning range was $-400 \mathrm{mV}$ to $+800 \mathrm{mV}$ in relation to corrosion potential. The Electrochemical Impedance Spectroscopy (EIS) measurements were performed with frequency ranging from $10 \mathrm{mHz}$ to $100,000 \mathrm{~Hz}$ with a $10 \mathrm{mV}$ disturbance ${ }^{8}$. The curves obtained by EIS were fitted and analyzed using the software Nova 2.0.

\section{Results and Discussion}

\subsection{Galvanostatic electrodeposition}

Composite coatings were obtained at a galvanosatic control and a chronopotentiometric monitoring was performed for the different cathodic current conditions investigated, according to Figure 1.

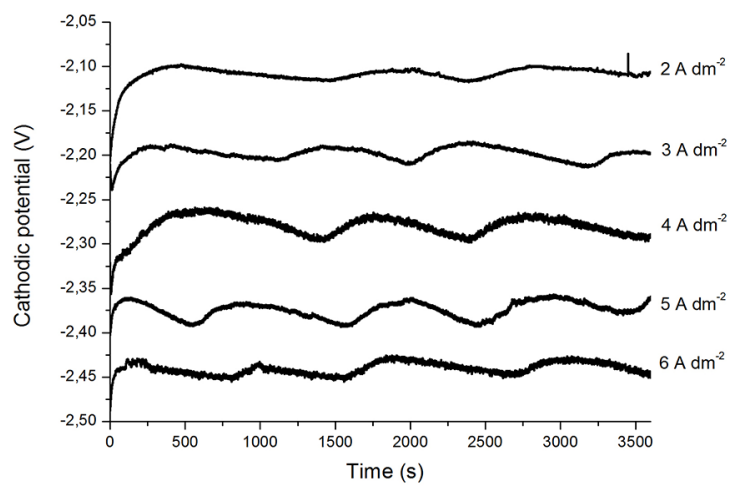

Figure 1. Chronopotentiometric monitoring for the galvanostatic deposition of the $\mathrm{Co}-\mathrm{Ni}$ / $\mathrm{SiC}$ composite on carbon steel.

Potentials attained for each condition as a consequence of applied current became more negative as the deposition current densities were more cathodic. Considering that the applied current density is fixed in each condition, the electrical resistance of the substrate varies as the deposit is formed once the surface is continuously altered, the potential transient is a measure of the reactions occurring at the interface. In this way, the oscillation of the potential occurs in response to the variation of the electrical resistance of the substrate surface in view of the nucleation and growth processes of the deposits ${ }^{16,17}$.

In the beginning, the potential tends to change due to the charge of the double electric layer until a reduction potential of the metallic ions in solution is reached. When the concentration of the electroactive species close to the working electrode (substrate) becomes close to zero, the potential becomes more negative to compensate for the capacitive effect ${ }^{16}$.

Table 2 shows the dependence of the current efficiency on the composition of the deposits. SiC contents in the composites were accounted in the calculations, since only nickel and cobalt ions were reduced on the substrate (cathode), while ceramic particles were only mechanically entrapped by the growing metallic layer ${ }^{6}$ :

$$
\begin{aligned}
& \eta=\frac{m_{M}}{m_{M, t}} \cdot 100 \%= \\
& \frac{m_{M / S i C}-m_{S i C}}{m_{M, t}} .100 \%
\end{aligned}
$$

where $\eta$ is current efficiency and $m_{M / S i C}, m_{M}$ and $m_{S i C}$ are mass of the composite, matrix, and $\mathrm{SiC}$ in the composite respectivelly. The mass of the composite was determined gravimetrically while the incorporated mass of $\mathrm{SiC}$ was calculated according to the content weight of the nanoparticles in the deposit. The theoretical mass of the matrix $m_{M}$ was found from the following formula ${ }^{6}$ :

$$
m_{M, t}=\frac{100 \% \cdot Q}{2 F\left(\frac{(\% C o)}{M_{C o}}+\frac{(\% N i)}{M_{N i}}\right)}
$$

where $Q$ is the total charge flowed through the circuit during electrolysis (determined colorimetrically); \% Co and $\% \mathrm{Ni}$ are percentages of cobalt and nickel in the deposit; $M_{C o}$ e $M_{N i}$ are molar mass of cobalt and nickel respectivelly.

The results confirmed the high efficiency of the cathodic process, since values exceeding $91 \%$ were achieved. The highest current efficiencies were obtained from the coatings produced in lower cathodic current densities, whose compositions presented higher levels of cobalt. Vaezi et al. observed that the addition of $\mathrm{SiC}$ nanoparticles in the galvanic bath promotes an increase on the current efficiency, although the immprovement of the deposition was not high ${ }^{18}$.

The process of deposition of the SiC particles have dependency coordination spheres formed around the surface of the nanoparticle. The use of SiC nanoparticles allows a higher surface area for adsorption of the load of present ionic species in the medium, favoring the formation of coordination spheres around these particles. By affinity species (ionic or partial polarization in the case of water) with the SiC particle, this will present different diffusion speeds to reach the substrate, depending on the type of active species involved $\left(\mathrm{Co}^{2+} ; \mathrm{Ni}^{2+} ; \mathrm{H}_{2} \mathrm{O}\right)^{5,7}$.

Some studies ${ }^{3,12}$ have shown that comparing to the Co$\mathrm{Ni}$ cyclic voltammogram, there is a lower cathodic current density at individual potential on $\mathrm{Co}-\mathrm{Ni} / \mathrm{SiC}$ voltammogram, indicating that the presence of $\mathrm{SiC}$ nanoparticles could inhibit the cathodic reduction of metallic cations. Thus, electrochemically, more energy is required for electrodeposition of $\mathrm{Co}-\mathrm{Ni} / \mathrm{SiC}$ coating than that of $\mathrm{Co}-\mathrm{Ni}$ coating. In addition, some authors ${ }^{4,8}$ consider that the increase of the current density tends to favor the increase of the reduction of hydrogen, reducing the current efficiency. Thus, the current efficiency values presented in Table 2 result from the not very defined contribution of the factors described above. 
Table 2. Cathodic current efficiency and composition of the nanocomposites.

\begin{tabular}{ccccc}
\hline \multirow{2}{*}{ Condition of coating } & \multirow{2}{*}{$\begin{array}{c}\text { Current } \\
\text { efficiency (\%) }\end{array}$} & \multicolumn{3}{c}{ Composition (wt.\%) } \\
\cline { 3 - 5 } & 97.54 & 71.41 & 25.39 & 3.20 \\
\hline $2 \mathrm{~A} \mathrm{dm}^{-2}$ & 96.84 & 67.94 & 27.13 & 4.93 \\
$3 \mathrm{~A} \mathrm{dm}^{-2}$ & 95.23 & 61.33 & 33.01 & 5.66 \\
$4 \mathrm{~A} \mathrm{dm}^{-2}$ & 91.77 & 52.35 & 40.53 & 7.12 \\
$5 \mathrm{~A} \mathrm{dm}^{-2}$ & 95.67 & 59.92 & 36.31 & 3.77 \\
$6 \mathrm{~A} \mathrm{dm}^{-2}$ & & & & \\
\hline
\end{tabular}

Table 2 also shows the composition of the composite coatings. It was seen that, despite the range of cathodic current densities, cobalt-rich composites were obtained. It shows that anomalous codeposition existis in the Co-Ni system, where the less noble metal (cobalt) is preferentially deposited, and in the coatings is higher (52-71 wt.\%) than in the bath (17 wt.\%). It is a well-known phenomenon, sice anomalous alloy deposition is characteristic of the iron-group metals $(\mathrm{Co}, \mathrm{Ni} \text { and } \mathrm{Fe})^{5}$.

For every four applied current densities, the amount of codeposited $\mathrm{SiC}$ nanoparticles in coatings increased rapidly. Beyond this value, wt. $\%$ of $\mathrm{SiC}$ decreased to the condition of $6 \mathrm{~A} \mathrm{dm}^{-2}$. The highest $\mathrm{SiC}$ content was observed in the condition of $5 \mathrm{~A} \mathrm{dm}^{-2}$ (7.12 wt.\%), while the smallest was in the condition of $2 \mathrm{~A} \mathrm{dm}^{-2}$ (3.20 wt.\%). Punctually, the increasing content of nickel followed the same behavior and could have improved incorporation of the ceramic phase. In the process of anomalous co-deposition, where the deposition occurs concurrently of the electroactive species present, the insertion of inert particles, which in the case of this work constitutes the ceramic phase (SiC), the effect and mechanism of deposition and coating formation will be influenced by the interactions of the ions present with these particles.

In Table 2, a trend is observed as a function of applied current that is not followed at the condition of $6 \mathrm{~A} \mathrm{dm}^{-2}$. Results that are not shown here indicate that, from $5.5 \mathrm{~A}$ $\mathrm{dm}^{-2}$, the increase in the deposition current density reflects in the elevation of Co content and decrease of the SiC content in the composites. This trend holds for higher current densities. There are cases in which the effects of the current density on the composition of the electrodeposit, depending on the type of codeposition, reflect in a confusing number of variations $s^{4,8}$. Only in systems where there is regular codeposition, this relationship can be totally predictable. In systems of anomalous codeposition, the content of the most noble metal in the alloy can either increase, decrease or remain virtually constant when the current density is varied ${ }^{5,9}$.

It has been reported in many studies that electrolytic deposition electrolyte with a higher concentration of inert particles, such as $\mathrm{SiC}$, results in a higher volume fraction of the particles in the coating, wich is governed by the adsorption of particles on the substrate's surface, by a two-step adsorption model. In the first step, the dispersed particles (cloud of particles) in the bath are transported to the surface of the electrode by mechanical action and an electric field, than are physically adsorbed due to the fluidal stirring (magnetic or ultrasson). In the second step, these physically adsorbed particles dehydrate because of the strong electric field of Helmholtz layer of the electrode, and a strong irreversible chemical adsorption of particles on the electrode takes place. The adsorbed particles are embedded by reduced metal or alloys $^{5,8,10}$. Thereby, the SiC nanoparticles in the electrolyte are adsorbed on the cathode until a saturation status is reached, where the number of codeposited SiC particles equals the number of SiC particles approaching the cathode surface ${ }^{11}$.

At lower current densities, deposition of metal ions on the surface of the substrate is preferred over $\mathrm{SiC}$ particles. With increasing current density, more energy is provided to increase convection and diffusion of the "cloud" of particles, resulting in the increase of the content of SiC particles in the coating ${ }^{11,20}$. However, when cathodic current density exceeds a certain value, in this work $5 \mathrm{~A} \mathrm{dm}^{-2}$, a further increase in current density would not affect the mobility of the inert particles, but would increase the mobility of the metal ions $\mathrm{s}^{3,4}$. For this reason, the concentration of particles of $\mathrm{SiC}$ in the coating decreases in $6 \mathrm{~A} \mathrm{dm}^{-2}$.

\subsection{Morphology of the deposits}

Figure 2 shows the surface morphology of $\mathrm{Co}-\mathrm{Ni} / \mathrm{SiC}$ composite coatings preprared at the range of current cathodic density of $2-6 \mathrm{~A} \mathrm{dm}^{-2}$. It is seen that the coatings develop a branched, acicular structure. With the increase in the current density, the acicular structure transforms into a partially nodular structure, where the acicular trunks become shorter and closer to the branche's length. The coatings obtained at the higher current densities showed less porous morphology, finer and more compact in terms of structure. Figure 2.f shows the morphology of the $\mathrm{SiC}$ nanoparticles deposited in the coating of $2 \mathrm{~A} \mathrm{dm}^{-2}$. Apparently, the agglomeration of the $\mathrm{SiC}$ particles ocurrs resulting in the generation of particle clouds, with an average size of about $900 \mathrm{~nm}$, engulfed in the Co-Ni coating matrix as second phases.

\subsection{XRD Characterization}

Figure 3 shows the XRD spectra of the coatings prepared under the conditions of $2 \mathrm{~A} \mathrm{dm}^{-2}$ and $5 \mathrm{~A} \mathrm{dm}^{-2}$. Peaks of small intensity in the range of $2 \theta$ of $20-40^{\circ}$ and individually 42.68 ; 45.72; 75.36 and 78.05 indicate the presence of $\mathrm{SiC}$ with rhombohedral centered structure.

Considering that the content weight of $\mathrm{SiC}$ is less than $10 \%$ for all the coatings obtained, and that $\mathrm{Co}$ and $\mathrm{Ni}$ concentrations are higher, the peaks related to the presence of $\mathrm{SiC}$ in the coatings are weak. Furthermore, since both $\mathrm{Ni}$ and Co salts are present in the electrolytic bath, a solid two- 


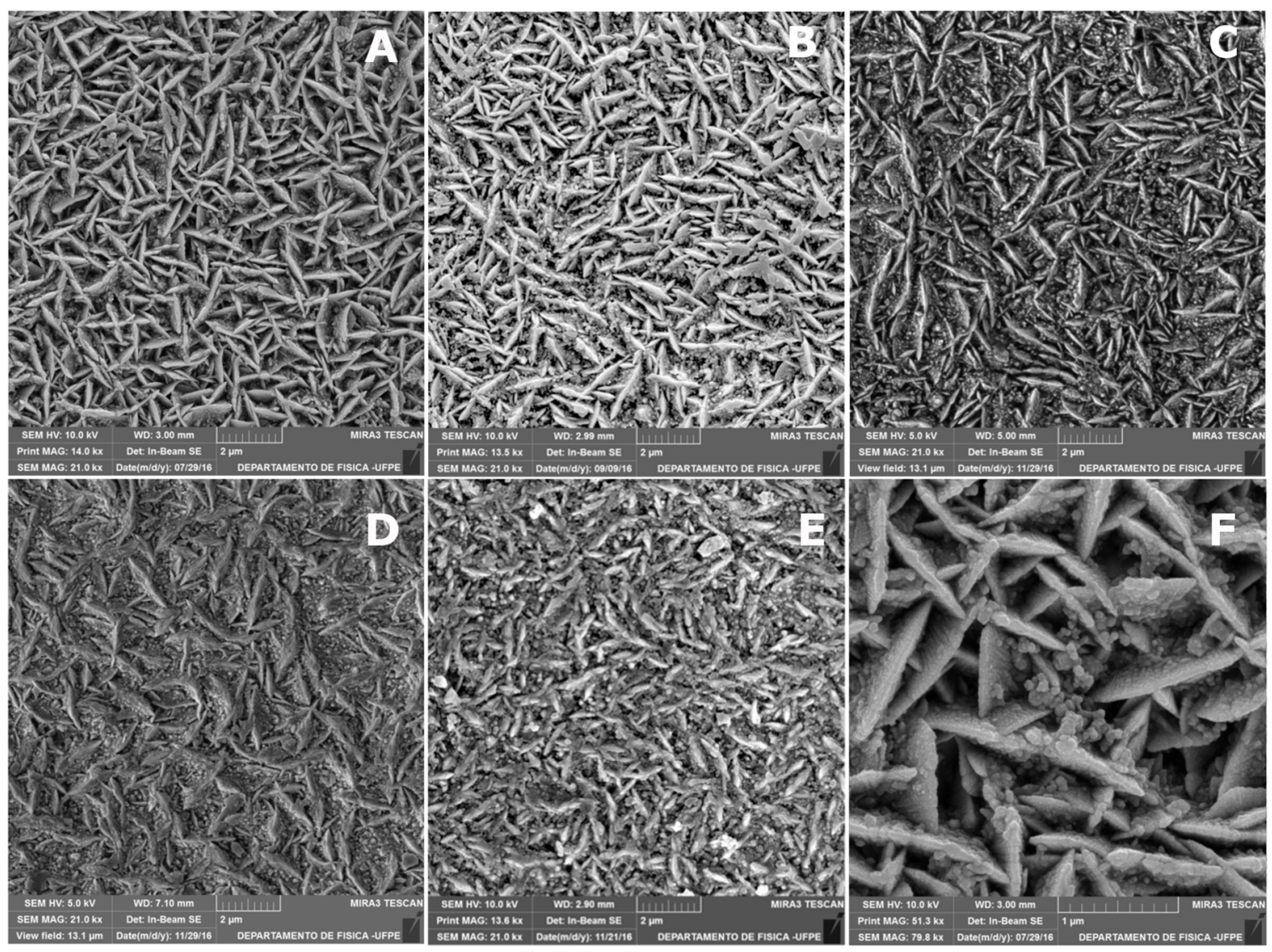

Figure 2. SEM morphology of $\mathrm{Co}-\mathrm{Ni} / \mathrm{SiC}$ coatings prepared at galvanostatic deposition of density currents: (A) $2 \mathrm{~A} \mathrm{dm}^{-2}$; (B) $3 \mathrm{~A} \mathrm{dm}^{-2}$; (C) $4 \mathrm{~A} \mathrm{dm}^{-2}$; (D) $5 \mathrm{~A} \mathrm{dm}^{-2}$; (E) $6 \mathrm{~A} \mathrm{dm}^{-2}$. (F) $\mathrm{SiC}$ nanoparticles deposited in the coating $2 \mathrm{~A} \mathrm{dm}^{-2}$.
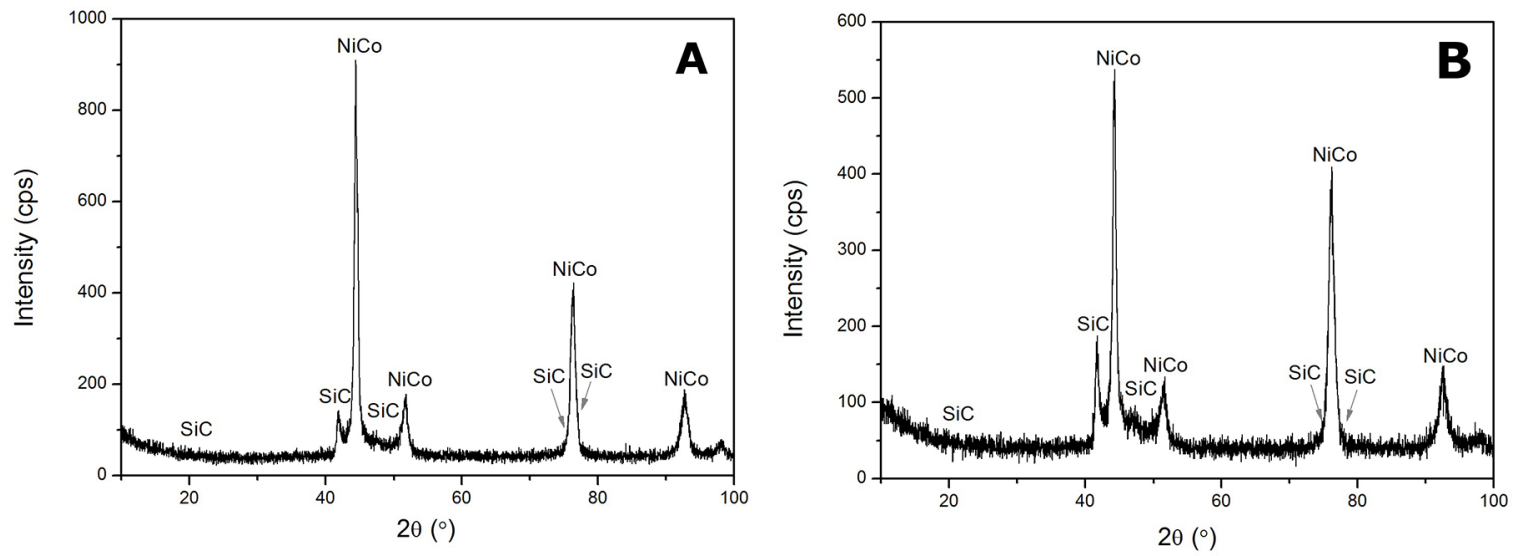

Figure 3. XRD diffractogram of Co-Ni/SiC composite coating. A) $2 \mathrm{~A} \mathrm{dm}^{-2}$ and B) $5 \mathrm{~A} \mathrm{dm}^{-2}$.

phase solution, which is rich in $\mathrm{NiCo}$, has been formed and identified. The diffractograms illustrate that the matrix of the composite coating is composed of a solid solution of $\mathrm{Ni}-\mathrm{Co}$ with a face-centered cubic (FCC) crystalline structure, with preferred orientation of the plane (220) followed by (111), (311) and (200). These planes correspond to the respective values of : $44.46^{\circ} ; 76.26^{\circ} ; 92.62^{\circ}$ e $51.60^{\circ}$. The change in the deposition current density conditions altered neither the preferred orientation of a plane nor the phase structure of the coatings obtained. In general, single-phase materials are more resistant to corrosion than multiphase materials because galvanic cells can be formed between the phases (along the grain boundary) and facilitate corrosion ${ }^{6}$. In addition, the corrosion resistance of the face-centered cubic unit is higher because of the higher atomic packing factor ${ }^{3}$. 
However, careful observation of Figure 3 reveals different peak intensities corresponding to different planes of cobalt and nickel according to the change in current density conditions. For the systematic study of texturing, the texture coeficient (TC) of each plane of all the samples was calculated using the following equation ${ }^{19}$ :

$$
T C_{(h k l)}=\frac{I_{(h k l)} / I_{(h k l)}}{\sum\left(I_{(h k l)} / I_{0(h k l)}\right)} \cdot 100 \%
$$

where $I_{(h k l)}$ is the intensity obtained from the textured sample and $I_{0(h k l)}$ is the intensity of the standard oriented sample; i.e., from JCPDS data. To enumerate the effect of current density on morphology, Scherrer's equation ${ }^{19}$ was used to calculate the crystallite size based on the higher angle reflection. Table 3 shows the TC and grain size data obtained in the diffractograms.

Table 3. Effect of current density on grain size and texture coefficient.

\begin{tabular}{cccccc}
\hline \multirow{2}{*}{$\begin{array}{c}\text { Condition of } \\
\text { coating }\end{array}$} & \multirow{2}{*}{$\begin{array}{c}\text { Grain size } \\
(\mathrm{nm})\end{array}$} & \multicolumn{5}{c}{ Texture coefficient (\%) } \\
\cline { 3 - 6 } & 105.01 & 12.83 & 5.54 & 55.57 & 26.06 \\
\hline $2 \mathrm{~A} \mathrm{dm}^{-2}$ & 98.85 & 15.66 & 7.11 & 52.46 & 24.87 \\
$3 \mathrm{~A} \mathrm{dm}^{-2}$ & 82.19 & 17.30 & 8.48 & 52.36 & 20.82 \\
$4 \mathrm{~A} \mathrm{dm}^{-2}$ & 53.97 & 18.24 & 10.23 & 45.03 & 27.44 \\
$5 \mathrm{~A} \mathrm{dm}^{-2}$ & 56.28 & 20.95 & 10.58 & 55.25 & 13.25 \\
$6 \mathrm{~A} \mathrm{dm}^{-2}$ & & & & & \\
\hline
\end{tabular}

The percentage of $\mathrm{TC}_{(\mathrm{hkl})}$ changes as a function of the deposition current density. Since the preferred orientation of a plane $(h k l)$ is shown ${ }^{8}$ by $\mathrm{TC}_{(\mathrm{hkl})} \geq 33.33 \%$, it can be seen that the preferred orientation of a plane in all coatings studied is (220). Although the crystalline structure found in the coatings is FCC, which has the highest packing fator, the preferential orientation (220) has the lowest packing density between the identified planes. It is interesting to note that, in the condition of $5 \mathrm{~A} \mathrm{~cm}^{-2}$, the decrease of the TC to the plane (220) is accompanied by the CT elevation of the other planes, all with higher packing density. Consequently, $\mathrm{Co}-\mathrm{Ni} / \mathrm{SiC}$ composite coatings obtained in the $5 \mathrm{~A} \mathrm{~cm}^{-2}$ are expected to exhibit better corrosion resistance due to the smaller amount of the plane (220), when compared to the other conditions of current.

On the other hand, grain size is an important factor for evaluating the mechanical properties of a polycrystalline material, especially hardness and corrosion resistance. Studies have shown that the incorporation of reinforcing particles promotes nucleation rate and reduces grain growth, and is an effective way to increase the micro-hardness of composite coatings $^{2,7}$. The decrease in grain size was observed as the current density increases, together with the increase in the amount of nanoparticles incorporated in the coating, acting as a grain refiner. This showed that, with increasing current density, the grain size in the coating decreases.

\subsection{Micro-hardness of the deposits}

Figure 4 shows the effect of the galvanostatic deposition on the micro-hardness and the $\mathrm{SiC}$ content of the $\mathrm{Co}-\mathrm{Ni}$ / $\mathrm{SiC}$ nanocomposite coatings. The micro-hardness is initially intensified by increasing the deposition current density, and becomes maximal at a $5 \mathrm{~A} \mathrm{dm}^{-2}$ condition. Comparing the behaviour of the data on the micro-hardness and the $\mathrm{SiC}$ content in the nanocomposite coating, it was observed that both presented a similar behaviour in response to the current density condition. It should be noted that micro-hardness measurements were not performed in the cross-section because it was found that not all samples had enough thickness for the indentations.

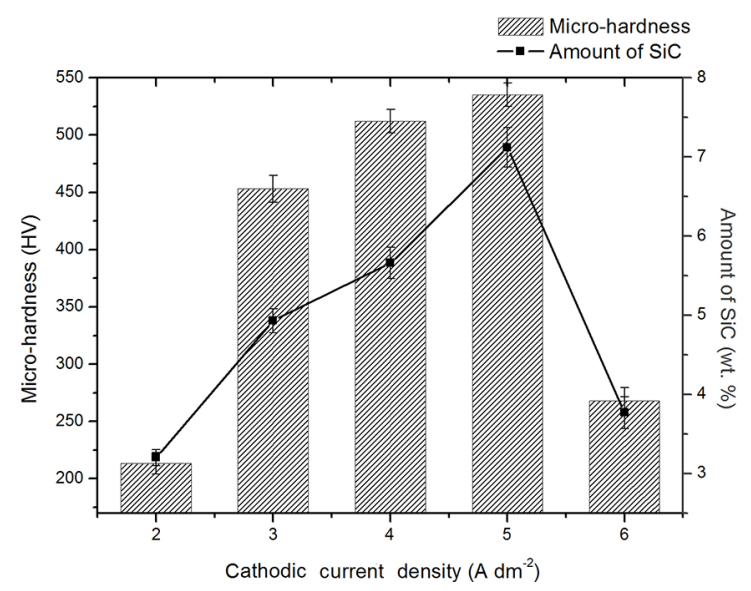

Figure 4. Effect of current cathodic density on micro-hardness and amount of $\mathrm{SiC}$ nanoparticles deposited in $\mathrm{Co}-\mathrm{Ni}$ metal matrix.

The micro-hardness of the coating obtained in the condition of $2 \mathrm{~A} \mathrm{dm}^{-2}$ presented the lowest values, probably due to the lower $\mathrm{SiC}$ content in the sample and the existence of microvessels in the nanocomposite structure ${ }^{12}$. Studies have shown that the microvessel formation decreases the micro-hardness of the coating and their number decreases with increasing deposition current density ${ }^{5,9}$. The microhardness of the composite coatings is determined by the properties of the reinforcing particle and the metal matrix. In the present study, the decrease in cobalt content and increase in nickel and $\mathrm{SiC}$ contents in the coating were observed as the deposition current density was increased up to $5 \mathrm{~A} \mathrm{dm}^{-2}$. This resulted in the behavior depicted in Figure 4.

The micro-hardness of the base metal was about $(252 \pm 8)$ $\mathrm{HV}$, close to that found for current densities of $2 \mathrm{~A} \mathrm{dm}^{-2}$ and 6 $\mathrm{Adm}^{-2}$. It is expected that the cathodic current density would affect the coating thickness, and thus the coating properties and performance. It is known that the thickness of the coating increases with the increasing current density ${ }^{2,4,8}$. The present results demonstrate that the coating thickness is not the critical factor affecting the coating performance. The thicknesses of the coatings were approximately $30,47,64,71$ and $82 \mu \mathrm{m}$ 
for $2,3,4,5$ and $6 \mathrm{~A} \mathrm{dm}^{-2}$ current density respectively. As seen in Figure 4 and Table 2, the amount of SiC content in the coating is the highest at $5 \mathrm{~A} \mathrm{dm}^{-2}$. Although the coating thickness is not the maximum at this current density, the hardness is the highest as seen in Figure 4. These results indicate that the hardness was affected more significantly by the amount of codeposited $\mathrm{SiC}$ in the coating rather than the coating thickness.

\subsection{Potentiodynamic polarization (PP)}

The polarization curves of the $\mathrm{Co}-\mathrm{Ni} / \mathrm{SiC}$ coatings and base metal were given in Figure 5. The corrosion potential $\left(E_{\text {corr }}\right)$ and corrosion current density $\left(j_{\text {corr }}\right)$ were calculated from the intersection of the cathodic and anodic Tafel curves using the Tafel extrapolation method. The polarization resistance $(R p)$ was determined using the Stern-Geary equation ${ }^{20}$ :

$$
R p=\frac{\left(\beta_{a} \cdot \beta_{c}\right)}{2,303 . j_{c o r r} \cdot\left(\beta_{a}+\beta_{c}\right)}
$$

where $\beta_{a}$ and $\beta_{c}$ are the anodic and cathodic Tafel slopes. The corrosion rate ( $r_{\text {corr }}$ in mm per year) was calculated by the following equation ${ }^{20}$ :

$$
r_{\text {corr }}=0,00327 \cdot \frac{i_{c o r r} \cdot M}{n . d}
$$

where $M, n$ and $d$ are the molar mass, electrochemical equivalent and the density of the metal tested respectively. The calculated results were listed in Table 4.

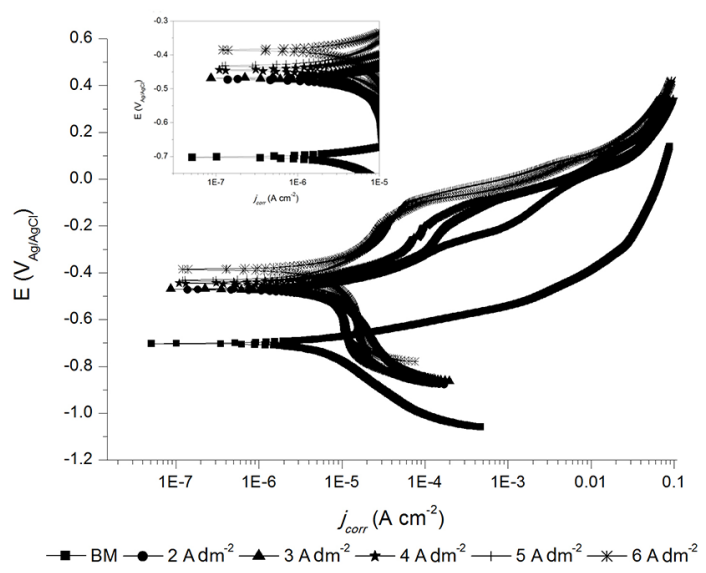

Figure 5. Potentiodynamic polarization curves of $\mathrm{Co}-\mathrm{Ni} / \mathrm{SiC}$ coatings and base metal in a $3.5 \mathrm{wt} . \% \mathrm{NaCl}$ solution.

The increase in the coating condition (cathodic current density) shifted the corrosion potential back to the potential of base metal. The corrosion potential of the $\mathrm{Co}-\mathrm{Ni} / \mathrm{SiC}$ coatings shifted to more positive potential values $(-0,47505$ $\mathrm{V}_{\mathrm{Ag} / \mathrm{AgCl}}$ to $\left.-0,38485 \mathrm{~V}_{\mathrm{Ag} / \mathrm{AgCl}}\right)$ than that of the base metal $\left(-0,70258 \mathrm{~V}_{\mathrm{Ag} / \mathrm{AgCl}}\right)$. This shift in corrosion potential suggests that the elaborate coatings have a dominant influence on the overall anodic reaction ${ }^{13,21}$. Comparing the current density conditions, this change in corrosion potential may also be associated with the amount of pores across the thickness of the coatings. To verify this conclusion, the electrochemical impedance spectroscopy tests were also conducted and discussed in the next section. It is obvious that the corrosion potential shift was followed by the corrosion current density decrease, decreasing the annual corrosion rate and increasing the polarization resistance $(R p)$ of the coatings (Table 4$)$.

\subsection{Electrochemical impedance spectroscopy (EIS)}

Electrochemical Impedance Spectroscopy measurements are useful to investigate the degradation of coatings and corrosion protection of different coatings for substrate ${ }^{21}$. Figures 6 and 7 show the Bode $\log |\mathrm{Z}|$ plot and Nyquist plot, respectively, for the coatings and the base metal in a 3.5 wt. $\% \mathrm{NaCl}$ solution.

The number of time constants of the EIE results have been determined by changes in the phase angle as a function of the frequency in the Bode plots (not shown here). Two time constants (i.e. two capacitive semicircles) can be observed in the graphs of Bode (Figure 6). The time constant at the higher frequencies is related to the coating response, while the one at lower frequencies is related to the charge transfer processes for the coatings reacting with the $\mathrm{NaCl}$ solution. According to literature, the high frequency region on the Bode plot provides information about coating defects and other changes in the surface area. The low frequency region is associated with the physicochemical phenomena at the interface metal-coating ${ }^{21,22}$. Moreover, the corrosion rate can be estimated by the value of the impedance modulus $(|\mathrm{Z}|)$ in the Bode plot. The higher value of $|Z|$ implies a lower corrosion rate for the coatings. It is clear that, with increasing $\mathrm{SiC}$ content in the coating, the corrosion resistance as well as the value of $|\mathrm{Z}|$ increases.

The capacitive arcs of the $\mathrm{Co}-\mathrm{Ni} / \mathrm{SiC}$ coatings and the base metal shown on the Nyquist plots (Figure 7) are similar regarding their shape, they only differ considerably in their sizes. This indicates that the corrosion process might follow the same mechanism. For the Nyquist plot, it can also be observed that the $\mathrm{Co}-\mathrm{Ni} / \mathrm{SiC}$ composite coating obtained at the $5 \mathrm{~A} \mathrm{dm}^{-2}$ condition (which had the highest $\mathrm{SiC}$ content) exhibits the biggest semicircle radius compared to the other composite coatings and base metal.

For the purpose of adjusting and analyzing the EIS data, a two-time constant equivalent circuit was selected and shown in Figure 8. $R_{\text {sol }}$ is placed in series with all other elements of the equivalent circuit, which represents the resistance of the electrolyte. $R_{c t}$ and $C P E_{d l}$ is the charge transfer resistance at metal-electrolyte interface and non-ideal double layer capacitance respectively. $R_{c}$ and $C P E_{c}$ is also related to the 
Table 4. Corrosion characteristic obtained from potentiodynamic polarization measurement for $\mathrm{Co}-\mathrm{Ni} / \mathrm{SiC}$ nanocomposite coatings and base metal.

\begin{tabular}{ccccc}
\hline Condition of coating & $\mathrm{E}_{\text {corr }}\left(\mathrm{V}_{\mathrm{Ag} / \mathrm{AgCl}}\right)$ & $j_{\text {corr }}(\mathrm{A} \mathrm{cm}-2)$ & $r_{\text {corr }}(\mathrm{mm} / \mathrm{year})$ & $R p\left(\mathrm{k} \Omega \mathrm{cm}^{2}\right)$ \\
\hline $\mathrm{BM}\left(0 \mathrm{~A} \mathrm{dm}^{-2}\right)$ & -0.70258 & $6.50 \mathrm{E}-03$ & 0,075499 & 4,858 \\
$2 \mathrm{~A} \mathrm{dm}^{-2}$ & -0.47505 & $5.93 \mathrm{E}-03$ & 0,065149 & 5,767 \\
$3 \mathrm{~A} \mathrm{dm}^{-2}$ & -0.46913 & $4.05 \mathrm{E}-03$ & 0,05447 & 7,749 \\
$4 \mathrm{~A} \mathrm{dm}^{-2}$ & -0.44308 & $4.96 \mathrm{E}-03$ & 0,04458 & 8,545 \\
$5 \mathrm{~A} \mathrm{dm}^{-2}$ & -0.43451 & $2.03 \mathrm{E}-03$ & 0,03239 & 10,427 \\
$6 \mathrm{~A} \mathrm{dm}^{-2}$ & -0.38485 & $2.40 \mathrm{E}-02$ & 0,026379 & 9,0268 \\
\hline
\end{tabular}

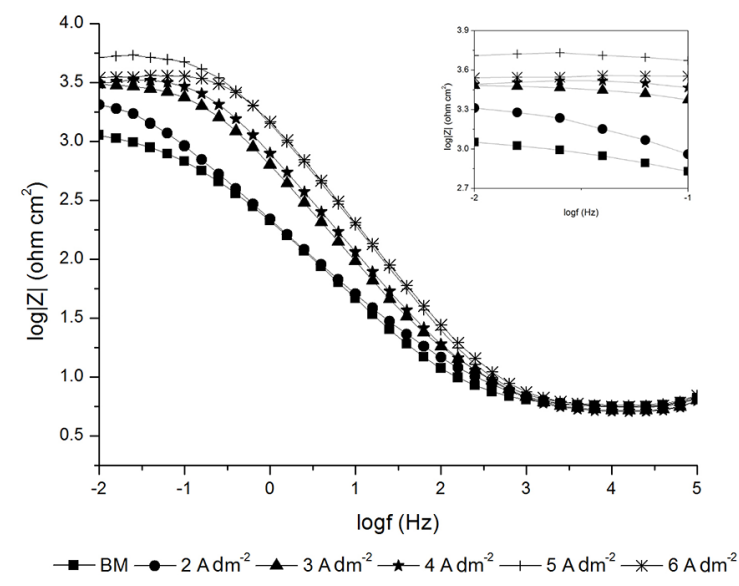

Figure 6. Bode $(\log |\mathrm{Z}|)$ diagrams for $\mathrm{Co}-\mathrm{Ni} / \mathrm{SiC}$ nanocomposite coatings and base metal in a $3.5 \mathrm{wt} . \% \mathrm{NaCl}$ solution.

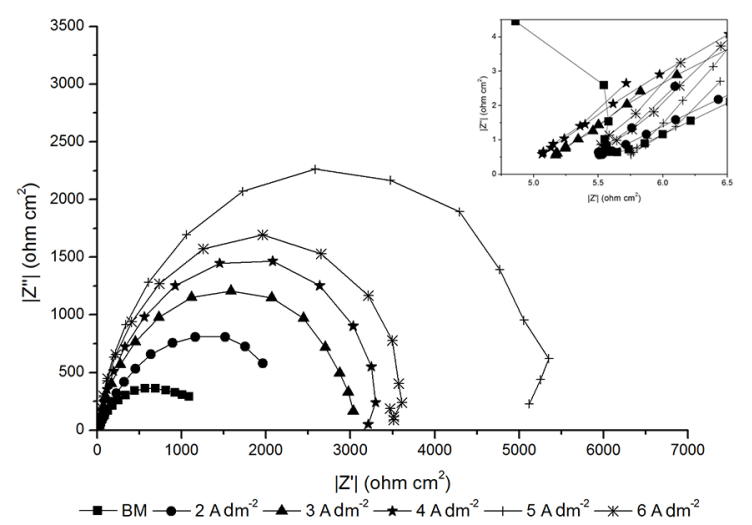

Figura 7. Nyquist diagrams of $\mathrm{Co}-\mathrm{Ni} / \mathrm{SiC}$ coatings and base metal in a $3.5 \mathrm{wt} . \% \mathrm{NaCl}$ solution.

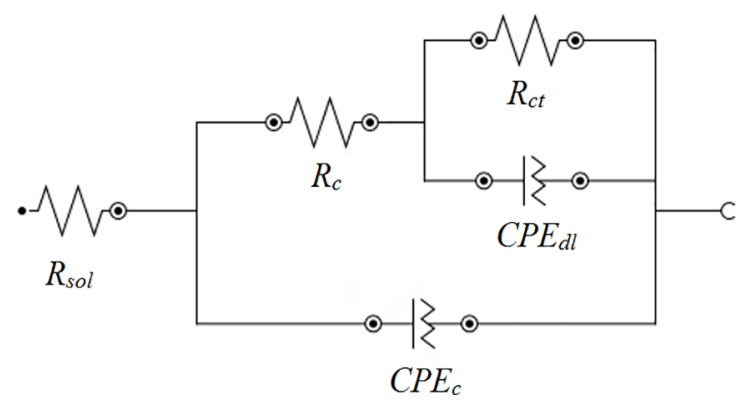

Figure 8. Equivalent circuit for $\mathrm{Co}-\mathrm{Ni} / \mathrm{SiC}$ coatings and base metal in a 3.5 wt. $\% \mathrm{NaCl}$ solution. non-ideal resistance and capacitance of the coating. In this work, the constant-phase element ( $C P E$ ) was used to represent the capacitances (double-layer capacitance and coating capacitance) due to the roughness and heterogeneity of the electrode surface. Furthermore, the choice of a constant-phase element provides a more accurate fitting of the impedance behavior of the electric double-layer and the coating since the effects of deviations from ideality were considered $d^{5,21}$.

$R_{c}$ is the resistance related to the conduction paths of ions, such as pores and cracks developed in the coating. This component reflects the ability to resist electrolyte penetration and may be used to assess the protective performance of the coatings. When the electrolyte penetrated the coating, the dielectric constant of the coating changed and, consequently, $C P E_{c}$ took on other values. It is important to note that permeation of the electrolyte in the coating is also related to the porosity and thickness ${ }^{4,23,24}$.

The equivalent circuit (Figure 8) was also adjusted for the electrolyte / base metal system considering $R_{c}$ and $C P E_{c}$ as the resistance and the non-ideal capacitance of the oxide layer formed during exposure to a $\mathrm{NaCl}$ solution. The values of the components obtained from the circuit fitted for the coatings and the base metal were shown in Table 5 .

As it can be seen in Table 5, the presence of coatings obtained by galvanostatic deposition resulted in an increase in the $R_{c}$ and a decrease in the $C P E_{c}$, when compared to the electrolyte / base metal system. At the $2 \mathrm{~A} \mathrm{dm}^{-2}$ condition, the coating showed an increase of $560 \%$ in the $R_{c}$ and a decrease of $16 \%$ in the $C P E_{c}$ values relative to the electrolyte / base metal system. Despite this increase in the corrosion resistance, the result was the least expressive when the other coatings are evaluated because, in this condition, the coating had the least thickness and lowest SiC content. Similar results were found in the potentiodynamic polarization in the previous item.

In a general manner, the $R_{c}$ assumed higher values steadily until reaching the condition of $5 \mathrm{~A} \mathrm{dm}^{-2}$, decreasing slightly to $6 \mathrm{~A} \mathrm{dm}^{-2}$. The $R_{c}$ relative to the $5 \mathrm{~A} \mathrm{dm}^{-2}$ condition was about $4370 \%$ higher than the $R_{c}$ of the base metal. This behavior follows the tendency observed in the SiC content in the coating since the deposit obtained in the condition of $5 \mathrm{~A} \mathrm{dm}^{-2}$ presented higher $\mathrm{SiC}$ content. This fact may be associated with the tendency of the SiC nanoparticles to fill 
Table 5. Electrochemical parameters fitted from EIS measurement for the electrolyte/coating and electrolyte/base metal systems.

\begin{tabular}{ccccccc}
\hline Condition of coating & $\begin{array}{c}R_{c} \\
\left(\Omega \mathrm{cm}^{2}\right)\end{array}$ & $\begin{array}{c}C P E_{c} \\
\left(\Omega \mathrm{cm}^{-2} \mathrm{~s}^{-\mathrm{n}}\right)\end{array}$ & $\mathrm{N}$ & $\begin{array}{c}R_{c t} \\
\left(\Omega \mathrm{cm}^{2}\right)\end{array}$ & $\begin{array}{c}C P E_{d l} \\
\left(\Omega \mathrm{cm}^{-2} \mathrm{~s}^{-\mathrm{n}}\right)\end{array}$ & $\mathrm{N}$ \\
\hline Base metal $\left(0 \mathrm{~A} \mathrm{dm}^{-2}\right)$ & 59 & $1.21 \times 10^{-3}$ & 0.637 & 1,380 & $25.7 \times 10^{-6}$ & 0.677 \\
\hline $2 \mathrm{~A} \mathrm{dm}^{-2}$ & 330 & $1.01 \times 10^{-3}$ & 0.662 & 2,670 & $11.5 \times 10^{-6}$ & 0.356 \\
$3 \mathrm{~A} \mathrm{dm}^{-2}$ & 1,700 & $338 \times 10^{-6}$ & 0.805 & 3,150 & $9.0 \times 10^{-6}$ & 0.288 \\
$4 \mathrm{~A} \mathrm{dm}^{-2}$ & 1,810 & $254 \times 10^{-6}$ & 0.836 & 4,080 & $9.0 \times 10^{-6}$ & 0.421 \\
$5 \mathrm{~A} \mathrm{dm}^{-2}$ & 2,580 & $128 \times 10^{-6}$ & 0.901 & 5,270 & $3.35 \times 10^{-6}$ & 0.344 \\
$6 \mathrm{~A} \mathrm{dm}^{-2}$ & 1,920 & $126 \times 10^{-6}$ & 0.884 & 4,350 & $9.0 \times 10^{-6}$ & 0.275 \\
\hline
\end{tabular}

some pores in the coating and prevent further diffusion of chloride ions along the interface ${ }^{23,24}$.

By observing the $C P E_{c}$, there is a tendency to reduce the capacitance of the coatings, reaching the lowest value for the $5 \mathrm{~A} \mathrm{dm}^{-2}$ condition. This behavior can also be attributed to the smaller contact area of the electrolyte deposits as well as the electrolyte access within the pores of the coating. In the case of the base metal, the $C P E_{c}$ is higher because of the larger contact area of the surface with the electrolyte. In this way, the corrosive medium passing through the coating pores have easily reached the coating/substrate interface. The results of polarization curves, presented in the previous item, also indicated similar results attributed to the porosity.

$R_{c t}$ represents resistance to charge transfer whose value is a measure of electron transfer across the surface and is inversely proportional to the corrosion rate ${ }^{13,22,24}$. An electric double layer is formed at the interface between the electrode (coating surface or base metal) and the surrounding electrolyte from the moment the immersion is initiated. The high $R_{c t}$ values and the low $C P E_{c}$ values imply that the coatings have a better corrosion protection capability. The $R_{c t}$ values of the $\mathrm{Co}-\mathrm{Ni} / \mathrm{SiC}$ composite coatings are obviously higher than the value for the base metal. The $R_{c t}$ values increase significantly with the increase in current density applied in obtaining the coating to the condiction of $5 \mathrm{~A} \mathrm{dm}^{-2}$, as can it be seen in the zoom of Figure 7. Additionally, it is observed that the behavior seen in $R_{c t}$ is analogous to that observed in the $\mathrm{SiC}$ content in the coating. According to Özkan et al. ${ }^{13}, R_{c t}$ increases dramatically with increasing $\mathrm{SiC}$ content in the composite coating. In their work, where several deposition parameters were considered, the load transfer resistance increased from 12.95 to $25.05 \mathrm{k} \Omega \mathrm{cm}^{2}$ by increasing the content of SiC codeposited from 1.4 to $5.9 \%$ by mass. Because $\mathrm{SiC}$ is a wide-band gap semiconductor i.e. a dielectric material, higher amount of $\mathrm{SiC}$ codeposition implies higher charge transfer resistance, $R_{c t}$.

Several factors could influence the corrosion resistance of coatings obtained by electrodeposition, including coating thickness, composition of coating, grain size, crystalline structure, surface features and heterogeneity of the coating that may impart different roughness characteristics ${ }^{14,25}$. Corrosion of Co-Ni matrix coatings could only take place on the free surface of composite and/or within the pores. If the surface of the substrate is completely covered, the corrosive species tend to diffuse along these pores to interact with the surface of the substrate. The SiC nanoparticles used in this study, although incorporated into the metal matrix, were not able to completely fill all the pores in the coating and allowed the penetration of chloride ions into the interface. However, a significant improvement in corrosion resistance was observed for $\mathrm{Co}-\mathrm{Ni} / \mathrm{SiC}$ composite coatings with higher SiC contents in their composition. According to Özkan et al. ${ }^{13}$, with the incorporation of $\mathrm{SiC}$ nanoparticles in the $\mathrm{Co}-\mathrm{Ni}$ matrix, the effective metal area prone to corrosion decreases. The polarization curves (Figure 5) and EIS plots (Figures 6 and 7) confirmed that the deposition of SiC particles in the composite coatings as well as the coating can help to prevent the corrosive pits from growing and contribute to accelerate the process of metal matrix passivation. Consequently, the corrosion resistance of the composite coatings can be improved.

\section{Conclusions}

Electrodeposition of $\mathrm{Co}-\mathrm{Ni} / \mathrm{SiC}$ nanocomposite coating using galvanosthatic control was studied. The influence of cathodic current density on surface behaviour, microstructure, micro-hardness and corrosion properties of $\mathrm{Co}-\mathrm{Ni} / \mathrm{SiC}$ electrodeposited in carbon steel were investigated. It is feasible to prepare $\mathrm{Ni}-\mathrm{Co} / \mathrm{SiC}$ nanocomposite with co-deposition galvanostatic technique in API 5L X80 steel. With the increase in cathodic current density, the morphology of the coatings changed from an acicular structure to a partially nodular structure, where the acicular trunks become shorter and closer to the branch's length. At the same time, the amount of nickel and $\mathrm{SiC}$ nanoparticles were significantly increased in the deposit until the condition of $5 \mathrm{~A} \mathrm{dm}^{-2}$.

The change in the cathodic current density altered neither the preferred orientation of the plane (220) nor the phase structure (FCC) of the coatings obtained although the decrease in grain size was observed as the current density increased. It was found that the micro-hardness was affected more significantly by the amount of codeposited $\mathrm{SiC}$ in the coating rather than the coating thickness.

The increase in cathodic current density acted producing deposits with corrosion potential shifted to more positive values in comparison with base metal indicating a dominant 
influence on the overall anodic reaction. This change in corrosion potential may also be associated with the amount of pores across the thickness of the coatings confirmed by EIS tests. The enhancement of the corrosion resistance has been obtained at a $5 \mathrm{~A} \mathrm{dm}^{-2}$ condition, wich is related to the higher amount of $\mathrm{SiC}$ particles, higher amount of nickel, more compact morphology, lower grain size and less porous. The corrosion rate of carbon steel was reduced significativally due to $\mathrm{Co}-\mathrm{Ni} / \mathrm{SiC}$ nanocomposite coating acting on the substrate.

\section{References}

1. Lari Baghal SM, Amadeha A, Heydarzadeh Sohia M, Hadavib SMM. The effect of SDS surfactant on tensile properties of electrodeposited $\mathrm{Ni}-\mathrm{Co} / \mathrm{SiC}$ nanocomposites. Materials Science \& Engineering: A. 2013;559:583-590.

2. Bakhit B. The influence of electrolyte composition on the properties of Ni-Co alloy coating reinforced by $\mathrm{SiC}$ nanoparticles. Surface \& Coatings Technology. 2015;274:324-331.

3. Yang Y, Cheng YF. Mechanistic aspects of electrodeposition of $\mathrm{Ni}-\mathrm{Co}-\mathrm{SiC}$ composite nano-coating on carbon steel. Electrochimica Acta. 2013;109:638-644.

4. Bakhit B, Akbari A. Effect of particle size and co-deposition technique on hardness and corrosion properties of Ni-Co/ $\mathrm{SiC}$ composite coatings. Surface and Coatings Technology. 2012;206(23):4964-4975

5. Özkan S, Hapçı G, Orhan G, Kazmanlı K. Electrodeposited $\mathrm{Ni} / \mathrm{SiC}$ nanocomposite coatings and evaluation of wear and corrosion properties. Surface and Coatings Technology. 2013;232:734-741.

6. Rudnik E, Syrek S. Studies on the Codeposition of SiC Nanopowder with Nickel, Cobalt, and Co-Ni Alloys. Journal of Coatings. 2014;2014:659697.

7. Wash FC, Ponce de Leon C. A review of the electrodeposition of metal matrix composite coatings by inclusion of particles in a metal layer: an estabilished and diversifying technology. Transactions of the IMF. 2014;92(2):83-98.

8. Bakhit B, Akbari A, Nasirpouri F, Hosseini MG. Corrosion resistance of Ni-Co alloy and $\mathrm{Ni}-\mathrm{Co} / \mathrm{SiC}$ nanocomposite coatings electrodeposited by sediment codeposition technique. Applied Surface Science. 2014;307:351-359.

9. Crousier J, Eyraud M, Crousier JP, Roman JM. Influence of substrate on the electrodeposition of nickel-molybdenum alloys. Journal of Applied Electrochemistry. 1992;22(8):749-755.

10. Devaneyan SP, Senthilvelan T. Electro co-deposition and Characterization of $\mathrm{SiC}$ in Nickel Metal Matrix Composite Coatings on Aluminium 7075. Procedia Engineering. 2014;97:1496-1505.

11. Baron AF, Guerrero J, González JM, Gómez A, Jurado A, Sánchez Sthepa H. Effect of Ni content on the microstructure, thermal properties, and morphology of $\mathrm{Ni}-\mathrm{SiC}$ nanocomposites produced by mechanical alloying. 2016 Nov. 12 [Epub ahead of print].

12. Yang Y, Cheng YF. Fabrication of Ni-Co-SiC composite coatings by pulse electrodeposition -- Effects of duty cycle and pulse frequency. Surface and Coatings Technology. 2013;216:282288.

13. ASTM International. ASTM B748 - 90 - Standard Test Method for Measurement of Thickness of Metallic Coatings by Measurement of Cross Section with a Scanning Electron Microscope. West Conshohocken: ASTM International; 2016.

14. ASTM International. ASTM E384 - 11e1 - Standard Test Method for Knoop and Vickers Hardness of Materials. West Conshohocken: ASTM International; 2011.

15. ASTM International. ASTM G3 14 - Standard Practice for Conventions Applicable to Electrochemical Measurements in Corrosion Testing. West Conshohocken: ASTM International; 2014.

16. Bard AJ, Faulkner LR. Electrochemical Methods: Fundamentals and Applications. $2^{\text {nd }}$ Ed. Hoboken: John Wiley \& Sons; 2001.

17. Ahmad YH, Mohamed AMA. Electrodeposition of Nanostructured Nickel-Ceramic Composite Coatings: A review. Internation Journal of Electrochemical Science. 2014;9:1942-1963.

18. Vaezi MR, Sadrnezhaad SK, Nikzad L. Electrodeposition of Ni-SiC nano-composite coatings and evaluation of wear and corrosion resistance and electroplating characteristics. Colloids and Surfaces A: Physicochemical Engineering Aspects. 2008;315(1-3):176-182.

19. Chen L, Wang L, Zeng Z, Xu T. Influence of pulse frequency on the microstructure and wear resistance of electrodeposited $\mathrm{Ni}-\mathrm{Al}_{2}-\mathrm{O}_{3}$ composite coatings. Surface and Coatings Technology. 2006;201(3-4):599-605.

20. Baghery P, Farzam M, Mousavi AB, Hosseini M. Ni-TiO, nanocomposite coating with high resistance to corrosion and wear. Surface and Coatings Technology. 2010;204(23):3804-3810.

21. Wolynec S. Técnicas Eletroquímicas em Corrosão. São Paulo: EDUSP; 2003

22. Krishnaveni K, Narayanan TSNS, Seshadri SK. Corrosion resistance of electrodeposited $\mathrm{Ni}-\mathrm{B}$ and $\mathrm{Ni}-\mathrm{B}-\mathrm{Si}_{3} \mathrm{~N}_{4}$ composite coatings. Journal of Alloys and Compounds. 2009;480(2):765-770.

23. Zhang S, Li Q, Yang X, Zhong X, Dai Y, Luo F. Corrosion resistance of AZ91D magnesium alloy with electroless plating pretreatment and $\mathrm{Ni}-\mathrm{TiO}_{2}$ composite coating. Materiais Characterization. 2010;61(3):269-276.

24. Liu X, Xiong J, Lv Y, Zuo Y. Study on corrosion electrochemical behavior of several different coating systems by EIS. Progress in Organic Coatings. 2009;64(4):497-503.

25. Zhang Z, Wu X, Jiang C, Ma N. Electrodeposition of Ni matrix composite coatings containing $\mathrm{ZrC}$ particles. Surface Engineering. 2014;30(1):21-25. 